Review Article

\title{
Long-Term Efficacy and Complications of Radiofrequency Thermocoagulation at Different Temperatures for the Treatment of Trigeminal Neuralgia
}

\author{
Tao Hong $(\mathbb{D}$, Yuanyuan Ding $(\mathbb{D}$, and Peng Yao $\mathbb{1}$ \\ Department of Pain Management, Shengjing Hospital of China Medical School, No. 36, Sanhao Street, Heping District, \\ Shenyang 110004, China \\ Correspondence should be addressed to Peng Yao; ypyp908@126.com
}

Received 26 October 2019; Revised 30 January 2020; Accepted 7 February 2020; Published 5 March 2020

Academic Editor: Robert J. Linhardt

Copyright (c) 2020 Tao Hong et al. This is an open access article distributed under the Creative Commons Attribution License, which permits unrestricted use, distribution, and reproduction in any medium, provided the original work is properly cited.

Trigeminal neuralgia (TN) is a common neuropathic pain that seriously affects the daily life of patients. Many invasive treatments are currently available for patients who respond poorly to oral carbamazepine or oxcarbazepine. Among them, radiofrequency (RF) treatment is a viable option with reliable initial and long-term clinical efficacy. The long-term analgesic effects of radiofrequency thermocoagulation (RFT) at high temperatures $\left(\geq 80^{\circ} \mathrm{C}\right)$ are not superior to those at relatively low temperatures $\left(60-75^{\circ} \mathrm{C}\right)$. In contrast, the higher the temperature, the greater the risk of complications, especially facial numbness, masticatory muscles weakness, and corneal hypoesthesia. Some patients even experience irreversible lethal complications. Therefore, we recommend low-temperature RFT $\left(60-75^{\circ} \mathrm{C}\right)$ for treatment of TN. The therapeutic effects of pulsed radiofrequency (PRF) are controversial, whereas PRF $\left(\leq 75^{\circ} \mathrm{C}\right)$ combined with RFT can improve long-term effects and decrease the incidence of complications. However, large-scale clinical trials are needed to verify the efficacy of the combination of PRF and RFT.

\section{Introduction}

Trigeminal neuralgia (TN) is a common neuropathic pain disorder with symptoms of transient, electric-shock-like pain affecting one or more branches of the trigeminal nerve. Talking, eating, brushing teeth, and slight touching of trigger point located in the oral or perioral region can induce severe and brief pain. Severe pain can affect the daily activities of patients. Those who experienced long-term pain often experience emotional changes, such as anxiety and depression. Epidemiological studies have shown that elderly women have a higher incidence than men (1.5-2.1 times more than men), and the annual prevalence of the disease is 12.6-28.9 cases per 10 million people [1-4]. Patients with severe TN who cannot be completely controlled by oral carbamazepine or oxcarbazepine or who are intolerant to the adverse effect of drugs can benefit from invasive surgery. Common surgical interventions include percutaneous balloon compression [5], microvascular decompression (MVD) [6], gamma knife radiosurgery [7], RFT [8, 9], PRF [10, 11], and intradermal and/or subcutaneous injections of Botox [12], intragasserian phenol glycerite [13], and peripheral alcohol [14].

Although there are some serious complications reported in prior studies [9, 15-20], RFT is still an effective treatment for TN that can instantly relieve pain in $90 \%-100 \%$ of cases $[15,17-19,21-24]$. Kanpolat et al. have observed 1561 patients who underwent single-procedure RFT [21]. The proportion of patients who were painless for 5 years and did not require oral medication was as high as $57.7 \%$. By 15 years, $42.2 \%$ of patients still had no recurrence of pain. Fouad observed 312 patients with TN [25]. The rate of pain relief after 2 years of RFT was as high as $97.2 \%$, and the rate of pain recurrence tracking to 8.8 years was only $7.6 \%$. Tang et al. have observed 1161 patients who underwent RFT via the Hartel anterior approach, and the pain relief rate was as high as $52 \%$ after 11 years [9]. The purpose of this review is to summarize the different temperatures utilizing RFT 
treatment for TN. Thus, we hope to reveal the optimal temperature suitable in RFT operation with best outcome.

\section{Principles of RF}

The main principle of RF treatment of TN is blockage pain signal conduction by high temperature up to $90^{\circ} \mathrm{C}$ to destroy the nerve (RFT) or modulation of the nociceptive nerve function of trigeminal nerve with temperature not exceeding $42^{\circ} \mathrm{C}$ (PRF). Two sets of technology can reduce the transmission of peripheral stimuli to the central nervous system, thereby preventing the disastrous pain. Although the pathogenesis of idiopathic trigeminal neuralgia is not completely clear, most scholars tend to believe that TN was associated with arterial or venous vascular compression, strategically located at the root entry zone. They recommended that MVD was the gold standard treatment for refractory $\mathrm{TN}$ and did not consider $\mathrm{RF}$ treatment to be involved in this pathogen [26, 27]. Prior clinical reports indicated that MVD can achieve similar or better results than RFT of the gasserian ganglion or trigeminal rootlets $[19,28,29]$. However, RFT is an alternative treatment for patients with recurrent TN after MVD, and it achieved good pain relief condition [23]. Therefore, by interfering with the function of the trigeminal nerve or destroying the integrity of its anatomical structure, therapeutic effects can be achieved.

\section{The Pain Relief Rate of RFT at Different Temperatures for TN Treatment}

There is no specific standard for temperature selection in RFT. A review of the published English literature indicated that the temperature for RFT varied widely among studies $\left(60^{\circ} \mathrm{C}\right.$ to $\left.95^{\circ} \mathrm{C}\right)$. The theoretical basis for choosing hightemperature RFT is the hypothesis that the recurrence rate of $\mathrm{TN}$ is correlated with the degree of postoperative sensory deficit $[9,22,30]$. In support of this possibility, Taha et al. [22] have reported that the recurrence rate within 4 years was $100 \%$ among patients with mild postoperative facial numbness, whereas the rate was only $10 \%$ over a period of 10 years among patients with dense hypalgesia. Notably, those with analgesia had the lowest recurrence rate within 15 years. In addition, previous animal experiments have reported that temperatures below $80^{\circ} \mathrm{C}$ can selectively damage the Аб and $\mathrm{C}$ unmyelinated nerve fibers without damaging the $\mathrm{A} \alpha$ and $\mathrm{A} \beta$ nerve fibers, thereby blocking pain transmission without affecting facial tactile sensation [31].

High-temperature RFT $\left(\geq 75^{\circ} \mathrm{C}\right)$ often leads to serious complications, such as severe facial numbness (84.7-100\%) [9, 25], ptosis (0.7\%) [9], keratitis (1.94-4.9\%) [16, 25], corneal ulcers $(0.6-2.6 \%)[9,21]$, diplopia (0.66\%) [9], abducens nerve damage $(0.66-0.8 \%)[15,21]$, transient vision loss and blindness (0.86\%) [15], mandibular deviation (4\%) [15], masticatory muscle weakness $(8-15.8 \%)[9,16]$, hearing loss $(0.4 \%)$ [9], cerebrospinal fluid leakage $(0.17 \%)$ [9], and even death $(1.8-4 \%)[9,32]$. Those complications would cause pain to patients and lead to disputes between doctors and patients. The pain relief rate of RFT at $\geq 80^{\circ} \mathrm{C}$ had no significant advantage over RFT at $60-75^{\circ} \mathrm{C}$. Kosugi et al. have reported the use of RFT at $90^{\circ} \mathrm{C}$ for patients with pain at the V2 and/or V3 branch, which achieved 1- and 2-year painlessness rates of $40.5 \%-80.2 \%$ and $17.1 \%-54.9 \%$, respectively [30]. Son et al. have reported that after using $80^{\circ} \mathrm{C}$ RFT to treat TN, the proportions of patients achieving BNI I and II within 38 months were $71 \%$ and $15.8 \%$, respectively [33].

Some studies use the recurrence rate as an indicator to assess the efficiency of high-temperature RFT for TN. The percentage of patients with recurrent pain ranged from $7.8 \%$ to $42.7 \%$ with tracking from 11.6 to 15 years $[15,21]$. However, there were some limitations to the studies. The studies did not provide a detailed definition of "pain relief" or specify whether the patients used medication to control pain after the procedure. In addition, they included patients with secondary trigeminal neuralgia (STN) who had received other invasive interventions without success. Nonetheless, high-temperature RFT was not superior to low-temperature RFT in terms of the longterm pain relief rate. Tang et al. have analyzed a total of 1161 patients retrospectively and divided them into $65-70^{\circ} \mathrm{C}, 75^{\circ} \mathrm{C}$, and $80-85^{\circ} \mathrm{C}$ groups according to the temperature used in the procedure [9]. Notably, there was no significant difference in the long-term pain relief rate among the three groups, thus suggesting that a higher temperature for RFT would not further increase long-term pain relief, and a temperature $>65^{\circ} \mathrm{C}$ can generate satisfactory analgesic effects.

To explore the optimal temperature for achieving efficacious treatment of RFT, we conducted a multicenter clinical observational study to evaluate the long-term efficacy of low-temperature RFT, including temperatures of $62^{\circ} \mathrm{C}, 65^{\circ} \mathrm{C}, 68^{\circ} \mathrm{C}, 70^{\circ} \mathrm{C}$, and $75^{\circ} \mathrm{C}$ for RFT $[16,34]$. Patients with STN or V1 division of TN were excluded, as well as those who did not respond to other invasive procedures. The probability of experiencing no pain and requiring no drugs (BNI I) was 94.2\%, 98.3\%, 98.8\%, 98.4\%, and 98.9\% at discharge; $83.8 \%, 90.1 \%, 91.4 \%, 94.3 \%$, and $94.4 \%$ at 1 year after the procedure; and $66.7 \%, 80.5 \%, 88.2 \%, 84.3 \%$, and $87.9 \%$ at 3 years after the procedure. These data suggest that the pain relief rates at discharge were similar at temperatures from $62^{\circ} \mathrm{C}$ to $75^{\circ} \mathrm{C}$. With a prolonged follow-up time, the pain relief rate in the $62^{\circ} \mathrm{C}$ and $65^{\circ} \mathrm{C}$ groups decreased more significantly than that in the $68-75^{\circ} \mathrm{C}$ groups. However, up to 5 years after procedure, $59 \%$ and $64.3 \%$ of patients were pain-free in the $62^{\circ} \mathrm{C}$ and $65^{\circ} \mathrm{C}$ groups, confirming that $62-65^{\circ} \mathrm{C}$ in RFT is an efficacious temperature. Yang et al. have achieved a satisfactory pain reduction rate with RFT at $60^{\circ} \mathrm{C}$; the proportion of patients whose pain reduction was $>90 \%$ during 3-month-3.6-year follow-up period was as high as $80 \%$, thus further supporting the efficacy and feasibility of low-temperature RFT [35]. In long-term followup, patients in the $75^{\circ} \mathrm{C}$ group appeared to have higher painfree rates than those in the $68^{\circ} \mathrm{C}$ and $70^{\circ} \mathrm{C}$ groups, but this difference was not statistically significant. Zhao et al. have also compared the effectiveness of RFT at $70^{\circ} \mathrm{C}$ and $75^{\circ} \mathrm{C}$ and have found no significant differences in the rates of excellent relief in the Kaplan-Meier actuarial curve [32]. 
In summary, no significant differences were observed in the rates of pain relief after $R F T$ at $\geq 80^{\circ} \mathrm{C}$ and $\leq 75^{\circ} \mathrm{C}$. The probability of excellent pain relief at temperatures of $60-65^{\circ} \mathrm{C}$ was inferior to that at $68-75^{\circ} \mathrm{C}$, whereas the analgesic effects were similar at $70^{\circ} \mathrm{C}$ and $75^{\circ} \mathrm{C}$ in some studies. Hence, we recommend RFT at $68-75^{\circ} \mathrm{C}$.

\section{Occurrence of Adverse Effects at Different Temperatures for RFT}

The most common adverse effects after RFT treatment include facial numbness, masseter muscle weakness, and decreased or absent corneal reflexes (see Table 1).

The short-term incidence of mild facial numbness after RFT treatment is reportedly $85 \%-100 \%[15,20,25,32,34$, $36,41,42]$, and facial numbness gradually decreases or disappears completely within 1 month. Long-term moderate facial numbness (BNI III) mainly occurs at temperatures $\geq 65^{\circ} \mathrm{C}$. More specifically, the incidence was $0.23 \%-3.19 \%$ in the $65-70^{\circ} \mathrm{C}$ group [36], $24.2 \%$ in the $75^{\circ} \mathrm{C}$ group [34], and $39.8 \%-97.4 \%$ in the $\geq 85^{\circ} \mathrm{C}$ group $[9,15]$. Severe facial numbness (BNI IV) mainly occurs at temperatures $\geq 75^{\circ} \mathrm{C}$, with an incidence of $3.2 \%$ at $75^{\circ} \mathrm{C}$ [34] and $5.3 \%-14.5 \%$ at $\geq 80^{\circ} \mathrm{C}[9,17]$.

Masticatory muscle weakness is usually associated with damage to the V3 branch (motor nerve), which is most likely to occur at temperatures $\geq 65^{\circ} \mathrm{C}$. The incidence rate is $0.22 \%$ $4.8 \%$ at $\leq 68^{\circ} \mathrm{C}[34,36]$, with a recovery time of approximately 6 months, $7.1 \%-12 \%$ at $70^{\circ} \mathrm{C}[37,42]$, and $25.81 \%-$ $44.12 \%$ at $75^{\circ} \mathrm{C}$ [34], with a recovery time of more than 1 year. Case reports have described permanent masseter muscle weakness or dysfunction [25].

Anatomically, the $\mathrm{V} 1$ division of the $\mathrm{TN}$ is adjacent to the oculomotor nerve, trochlear nerve, and abducens nerve. When higher temperatures are used in RFT, the coagulum size due to the radiofrequency probe increases in both length and diameter [43], thus potentially damaging the nerves near TN and causing severe complications, such as ptosis, limited eye movement, diplopia, and corneal ulceration. Therefore, the temperatures associated with V1 division should be selected with caution. Several studies have observed the specific temperature delivered to the V1 division. The incidence of decreased corneal reflex has been found to be $3.57 \%-17.5 \%$ at temperatures of $62-68^{\circ} \mathrm{C}[34,38]$. However, there are no reports of the disappearance of corneal reflexes. When the V1 division combined with V2 or/and V3, a higher stepped temperature from $70^{\circ} \mathrm{C}$ to $85^{\circ} \mathrm{C}$ was delivered to the V2 or/and V3. Decreased corneal reflexes were observed in a greater proportion of individuals, at $15.69 \%-$ $26.47 \%$ [20, 34, 38]. Moreover, ptosis, limited eye movement, diplopia, and corneal ulceration have been reported in the literature with temperatures of $70-90^{\circ} \mathrm{C}[9,21,23,44]$.

In summary, the incidence of adverse effects gradually increases with increasing RFT temperature. As the observation time increases, the degree of these adverse effects gradually lessens, but the recovery times vary with the temperature used for RFT. The incidence and severity of complications are lower at temperatures $<70^{\circ} \mathrm{C}$, and the recovery time is within 6 months. Severe facial numbness, permanent masticatory atonia, and corneal hypoesthesia are associated with using temperatures at $\geq 70^{\circ} \mathrm{C}$, and some patients had not recovered by the end of the 5-year followup. Notably, irreversible and severe complications have low occurrence rates at temperatures $\leq 65^{\circ} \mathrm{C}$ for RFT. The probability of complications at $75^{\circ} \mathrm{C}$ is three- to eightfold greater than that at $70^{\circ} \mathrm{C}$. These data suggest that inappropriately increasing the temperature for RFT can damage not only the Аб and $\mathrm{C}$ unmyelinated nerve fibers but also the $\mathrm{A} \alpha$ and $\mathrm{A} \beta$ fibers in a nonselective manner, thereby inducing severe complications [31], such as abducens nerve injury, diplopia, and vision loss at $95^{\circ} \mathrm{C}$ [15], as well as diplopia, hearing loss, and ptosis at $85^{\circ} \mathrm{C}$ [9].

\section{The Pain Relief Rate of RFT Combined with PRF for the Temperature of TN}

The magnetic field generated by PRF plays a therapeutic role by modulating the release of immune inflammatory mediators or inhibiting C-fiber activation and synaptic transmission [45]. PRF is effective for the treatment of neuropathic pain. Therefore, some researchers believe that PRF can produce good analgesic effects [20, 32, 36, 39, 40, 46-49]. However, the effectiveness of PRF for the treatment of TN remains controversial. The painlessness rate of the treatment is $0 \%-85.7 \%$ for 6 months and $0 \%-78.6 \%$ for 2 years. Luo et al. have explored the causes of the poor effects of PRF and have found that a higher output voltage and electrical field intensity result in better outcomes [50]. Chua et al. have suggested that shortening the pulsed width to $10 \mathrm{~ms}$, enhancing the frequency to $4 \mathrm{~Hz}$, and prolonging the treatment duration to 6 min can improve the long-term analgesic effect, at least to some extent [51].

RFT combined with PRF is a relatively new method for the treatment of $\mathrm{TN}$, especially for the $\mathrm{V} 1$ branch. This procedure (RFT at $62-75^{\circ} \mathrm{C}$ combined with PRF at $42^{\circ} \mathrm{C}$ ) can increase long-term efficacy (85\%-92\% effective rate for 1 year and $70 \%-92 \%$ for 2 years), while simultaneously minimizing the incidence of adverse effects [32, 36, 39], although there are some opposing opinions [20]. Nonetheless, large-scale clinical trials are needed to evaluate the effectiveness of RFT combined with PRF for the treatment of TN.

\section{Improving the Effectiveness and Feasibility of RFT}

Increasing the temperature is not the only effective way to improve the efficacy of RFT treatment. Regulating the distance between the tip of the needle and the target nerves is crucial. The target location should be in the junction between the third division and the trigeminal ganglion, which can effectively improve the postoperative effects [15]. In addition, three-dimensional computed tomography (CT) or neuronavigator-guided control can be used to improve the accuracy of the puncture by monitoring the direction and angle of the needle in real time $[52,53]$. This technology simplifies the puncture process and avoids severe intraoperative or postoperative side effects, such as damage to the 


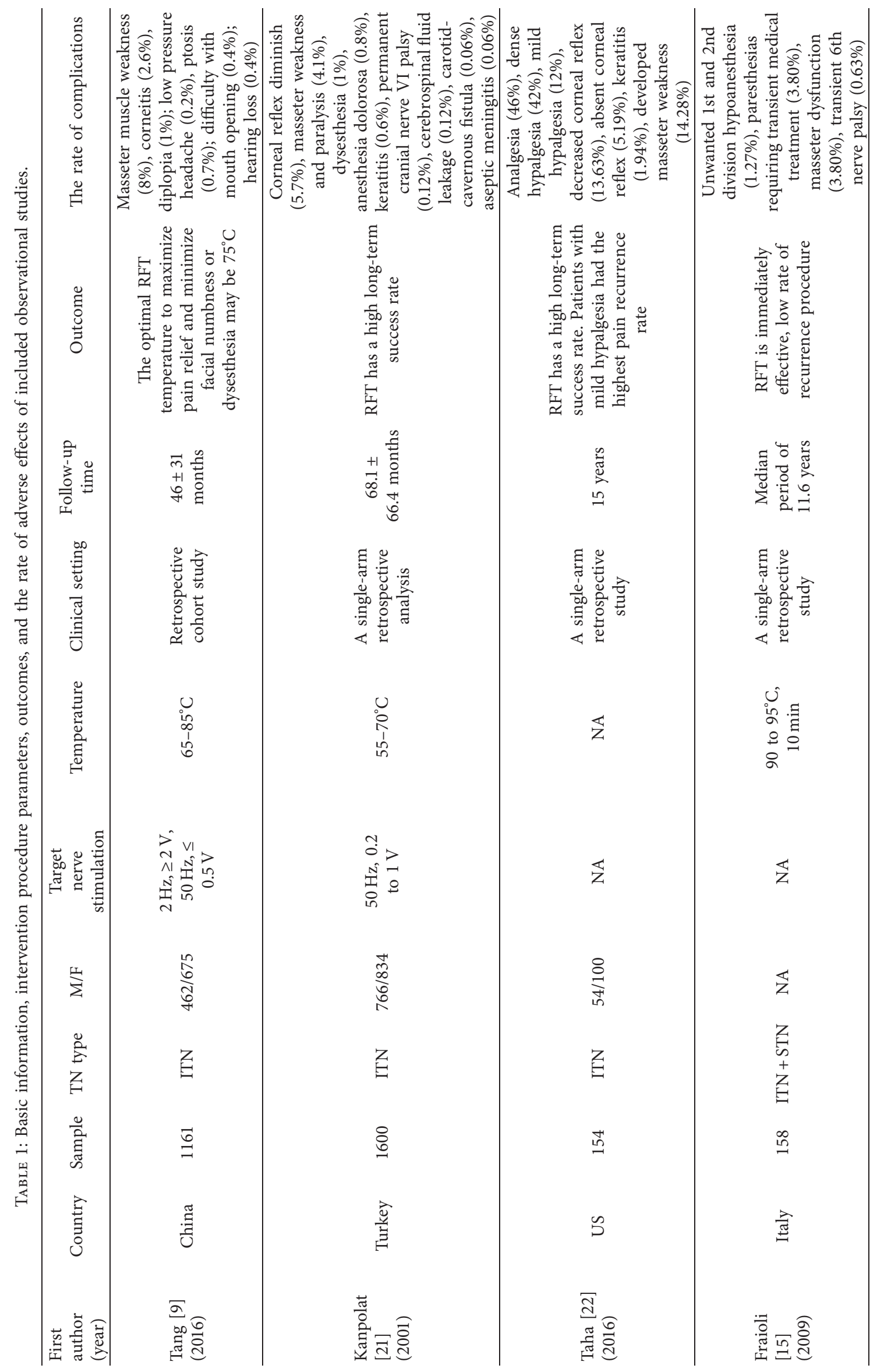




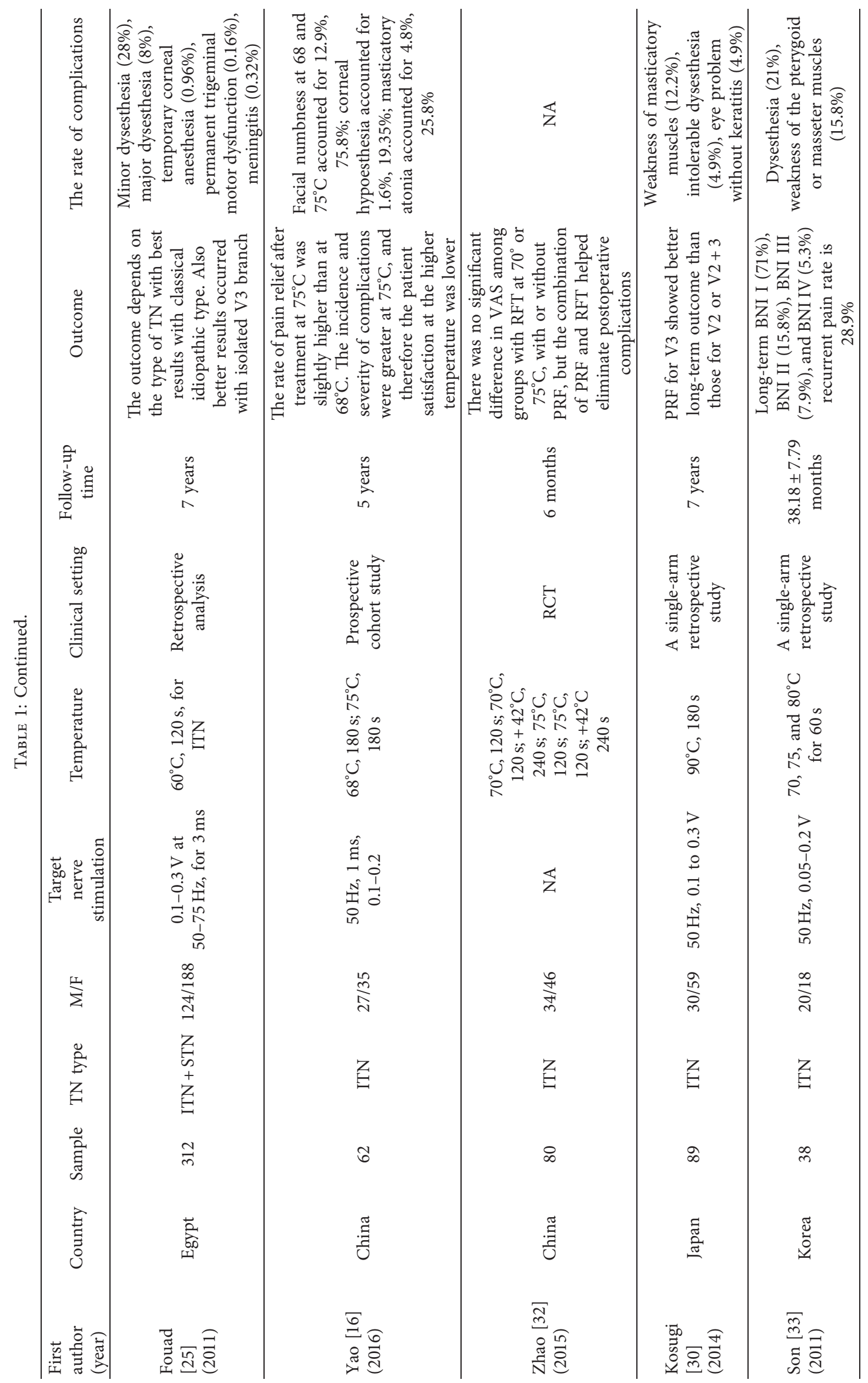




\begin{tabular}{|c|c|c|c|c|c|}
\hline 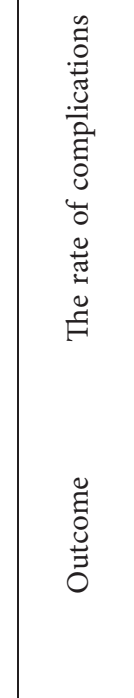 & 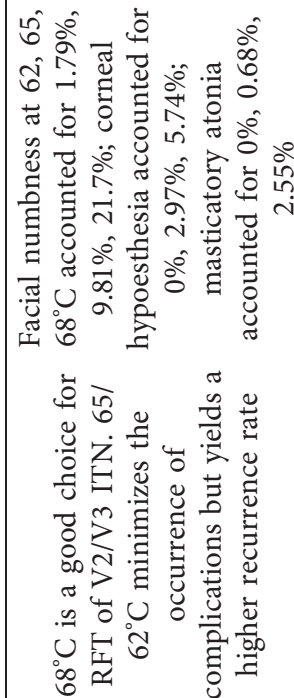 & 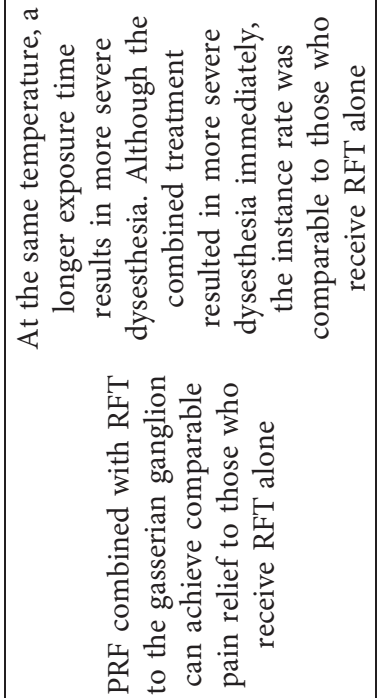 & 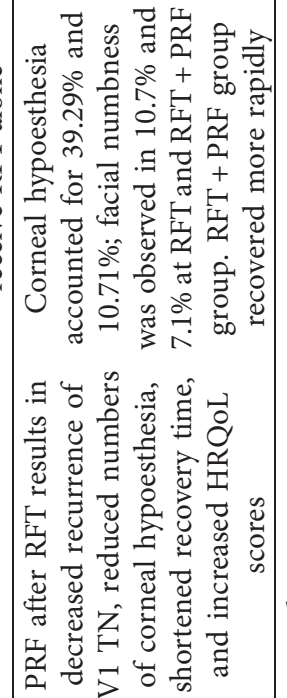 & 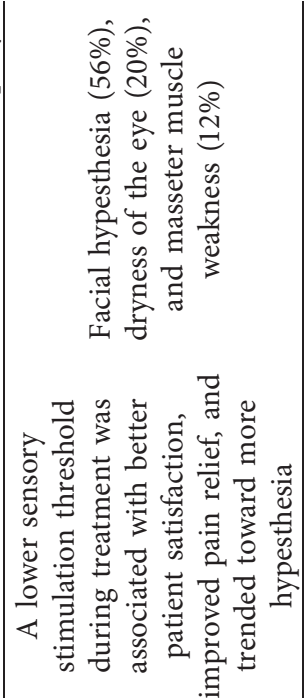 & 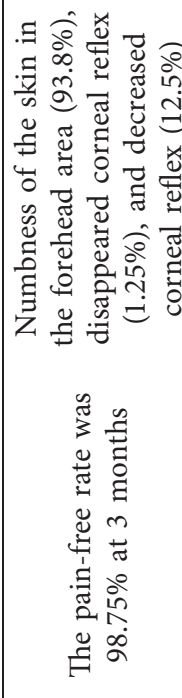 \\
\hline 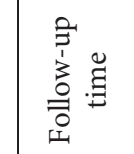 & 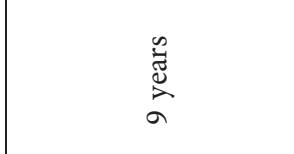 & 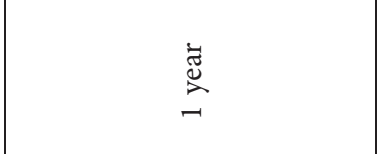 & 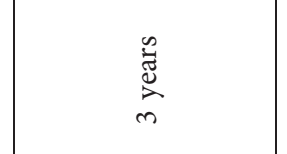 & 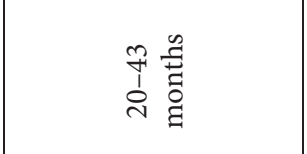 & 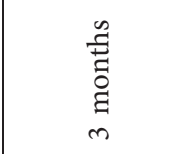 \\
\hline 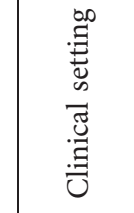 & 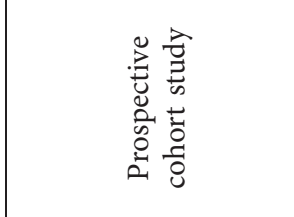 & 艺 & 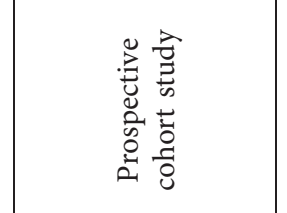 & 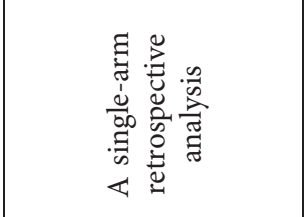 & 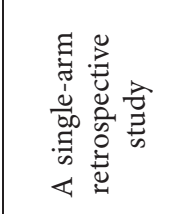 \\
\hline 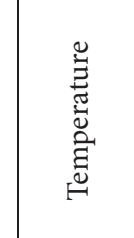 & 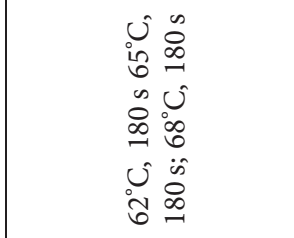 & 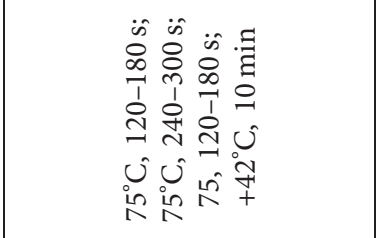 & 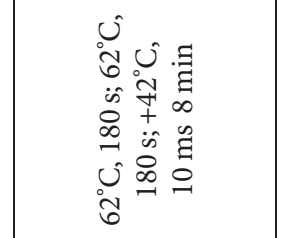 & $\begin{array}{ll}0 & 0 \\
0 & 0 \\
0 & \infty \\
1 & 1 \\
1 & 1 \\
0 & 0\end{array}$ & 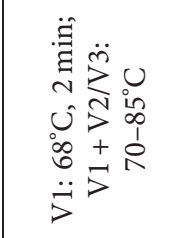 \\
\hline 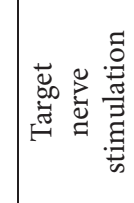 & 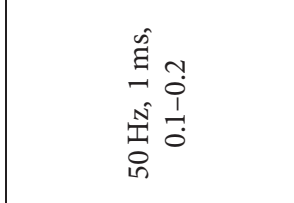 & 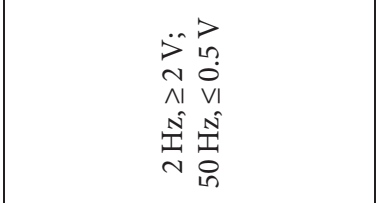 & 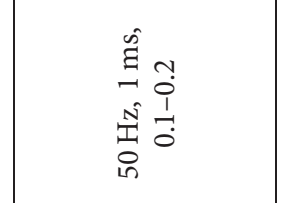 & 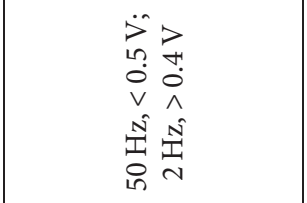 & $\overleftrightarrow{Z}$ \\
\hline$\stackrel{\text { 岁 }}{\Sigma}$ & 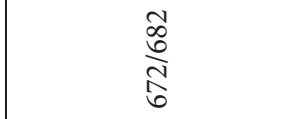 & $\frac{\hat{m}}{\hat{n}}$ & $\stackrel{\text { ले }}{\vec{m}}$ & 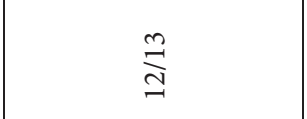 & $\frac{\pi}{2}$ \\
\hline $\begin{array}{l}\underset{\mathrm{a}}{\mathrm{S}} \\
\mathrm{Z}\end{array}$ & 冝 & Z & 忈 & 舀 & 忈 \\
\hline 䒕 & 岕 & 8 & ஜ & $\stackrel{\mathscr{n}}{\sim}$ & $\infty$ \\
\hline 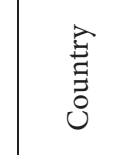 & తే: & 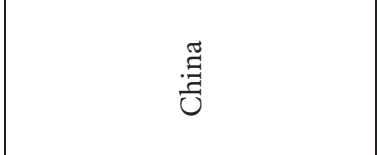 & 节 & 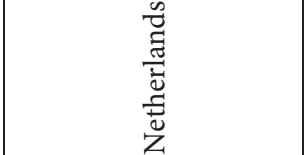 & 节 \\
\hline 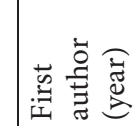 & 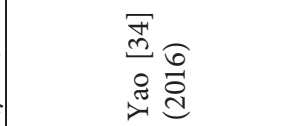 & 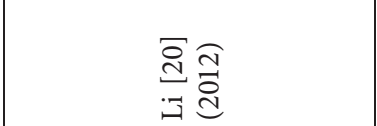 & 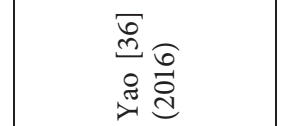 & 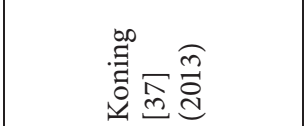 & 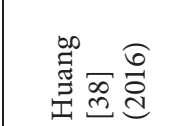 \\
\hline
\end{tabular}




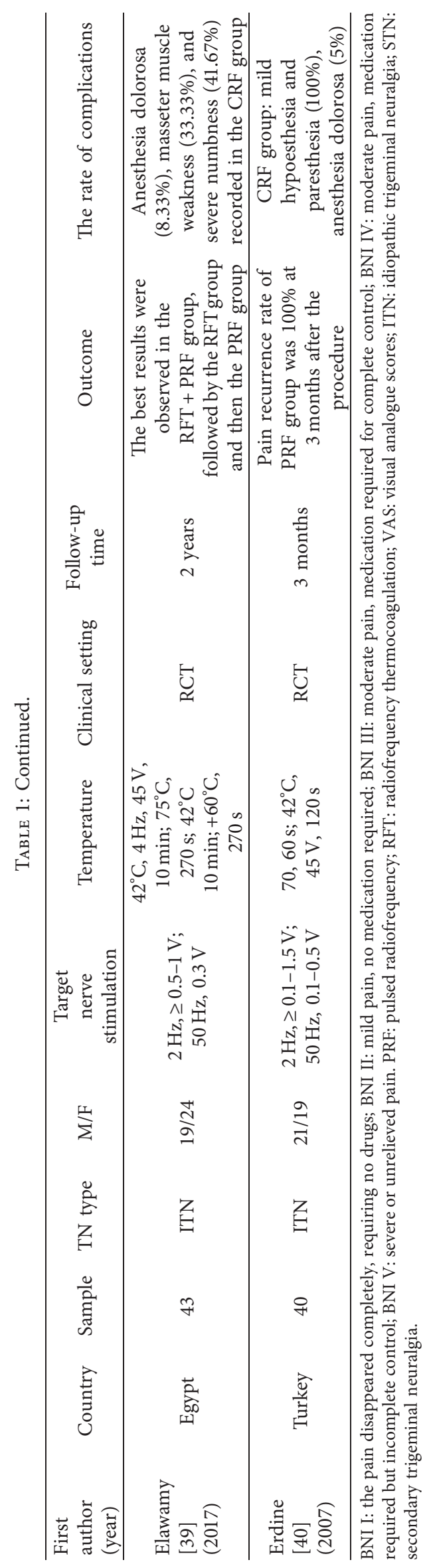


optic nerve, auditory nerve, internal carotid artery, and cavernous sinus. It is especially important to select the parameters of RFT. For example, at $<0.1 \mathrm{~V}$, an abnormal sensation or muscle contraction is induced in the areas controlled by the target nerves, suggesting that the needle tip is located in the nerve sheath. When RFT is performed, $A \alpha$ and $\mathrm{A} \beta$ fibers are destroyed nonselectively, rather than just the Аб and $C$ unmyelinated nerve fibers. Therefore, we recommended refraining from using high temperatures for RFT. If the above signs appear at $0.1-0.3 \mathrm{~V}$, the needle tip should be directed to the nerve root, and the temperature should be controlled to $\leq 70^{\circ} \mathrm{C}$. At $>0.3 \mathrm{~V}$, we suggest that the needle tip be at a certain distance from the nerve and be located near the ganglion. Consequently, only the small nerves (i.e., the $\mathrm{A} \sigma$ and $\mathrm{C}$ unmyelinated nerve fibers) will be heated, and the location of the needle tip should be adjusted to enhance efficiency $[9,37]$.

\section{Conclusion}

In summary, RF treatment is a safe, effective, and minimally invasive procedure of TN. An optimal temperature should be selected according to the branches of the trigeminal nerves involved in the RFT procedure. If $\mathrm{V} 1$ is involved, in order to decrease the risk of corneal reflex weakness or disappearing, a temperature of $\leq 65^{\circ} \mathrm{C}$ is recommended. If V2 and/or V3 are involved, $65-70^{\circ} \mathrm{C}$ temperatures are more suitable to effectively control pain and decrease the probability of adverse reactions. Too high temperature $\left(\geq 80^{\circ} \mathrm{C}\right)$ should be avoided because it could seriously damage the tissue and is associated with irreversible complications. In order to improve the accuracy of the puncture and decrease the complications of injuring crucial blood vessels and nerves caused by repeated punctures, it is better to use threedimensional CT or neuronavigator as guidance. Although the value of PRF for the treatment of TN remains controversial, RFT at $\leq 75^{\circ} \mathrm{C}$ combined with PRF is a feasible option, and further clinical trials are required to evaluate efficacy.

\section{Conflicts of Interest}

The authors declare no conflicts of interest regarding the publication of this paper.

\section{Authors' Contributions}

All authors contributed equally to this work.

\section{Acknowledgments}

Financial support was provided by Professor Peng Yao's Funding (no. 20170541032) from the Natural Science Foundation of Liaoning Province.

\section{References}

[1] J. S. Koopman, J. P. Dieleman, F. J. Huygen et al., "Incidence of facial pain in the general population," Pain, vol. 147, no. 1-3, pp. 122-127, 2009.
[2] J. P. Dieleman, J. Kerklaan, F. J. P. M. Huygen, P. A. D. Bouma, and M. C. J. M. Sturkenboom, "Incidence rates and treatment of neuropathic pain conditions in the general population," Pain, vol. 137, no. 3, pp. 681-688, 2008.

[3] G. C. Hall, D. Carroll, D. Parry, and H. J. McQuay, "Epidemiology and treatment of neuropathic pain: the UK primary care perspective," Pain, vol. 122, no. 1-2, pp. 156-162, 2006.

[4] G. Peters and T. J. Nurmikko, "Peripheral and gasserian ganglion-level procedures for the treatment of trigeminal neuralgia," The Clinical Journal of Pain, vol. 18, no. 1, pp. 28-34, 2002.

[5] P. Asplund, P. Blomstedt, and A. T. Bergenheim, "Percutaneous balloon compression vs percutaneous retrogasserian glycerol rhizotomy for the primary treatment of trigeminal neuralgia," Neurosurgery, vol. 78, no. 3, pp. 421-428, 2016.

[6] A. L. Ko, A. Ozpinar, A. Lee, A. M. Raslan, S. McCartney, and K. J. Burchiel, "Long-term efficacy and safety of internal neurolysis for trigeminal neuralgia without neurovascular compression," Journal of Neurosurgery, vol. 122, no. 5, pp. 1048-1057, 2015.

[7] J. Régis, C. Tuleasca, N. Resseguier et al., "Long-term safety and efficacy of Gamma Knife surgery in classical trigeminal neuralgia: a 497-patient historical cohort study," Journal of Neurosurgery, vol. 124, no. 4, pp. 1079-1087, 2016.

[8] H. S. Jin, J. Y. Shin, Y. C. Kim et al., "Predictive factors associated with success and failure for radiofrequency thermocoagulation in patients with trigeminal neuralgia," Pain Physician, vol. 18, no. 6, pp. 537-545, 2015.

[9] Y. Z. Tang, L. Q. Yang, J. N. Yue et al., "The optimal radiofrequency temperature in radiofrequency thermocoagulation for idiopathic trigeminal neuralgia: a cohort study," Medicine (Baltimore), vol. 95, no. 28, p. e4103, 2016.

[10] D. Thapa, V. Ahuja, C. Dass, and P. Verma, "Management of refractory trigeminal neuralgia using extended duration pulsed radiofrequency application," Pain Physician, vol. 18, no. 3, pp. E433-E435, 2015.

[11] F. Luo, T. Wang, J. J. Lu, and N. Ji, "Comparison of highvoltage- with standard-voltage pulsed radiofrequency of gasserian ganglion in the treatment of idiopathic trigeminal neuralgia," Pain Practice, vol. 15, no. 7, pp. 595-603, 2015.

[12] P. A. Kowacs, M. A. T. Utiumi, F. A. Nascimento, E. J. Piovesan, and H. A. G. Teive, "OnabotulinumtoxinA for trigeminal neuralgia: a review of the available data," Arquivos de Neuro-Psiquiatria, vol. 73, no. 10, pp. 877-884, 2015.

[13] J. Degn and J. Brennum, "Surgical treatment of trigeminal neuralgia. Results from the use of glycerol injection, microvascular decompression, and rhizotomia," Acta Neurochirurgica, vol. 152, no. 12, pp. 2125-2132, 2010.

[14] S. A. Shah, M. N. Khan, S. F. Shah, A. Ghafoor, and A. Khattak, "Is peripheral alcohol injection of value in the treatment of trigeminal neuralgia? An analysis of 100 cases," International Journal of Oral and Maxillofacial Surgery, vol. 40, no. 4, pp. 388-392, 2011.

[15] M. F. Fraioli, B. Cristino, L. Moschettoni, G. Cacciotti, and C. Fraioli, "Validity of percutaneous controlled radiofrequency thermocoagulation in the treatment of isolated third division trigeminal neuralgia," Surgical Neurology, vol. 71, no. 2, pp. 180-183, 2009.

[16] P. Yao, T. Hong, Z. B. Wang et al., "Treatment of bilateral idiopathic trigeminal neuralgia by radiofrequency thermocoagulation at different temperatures," Medicine (Baltimore), vol. 95 , no. 29, p. e4274, 2016.

[17] M. J. Teixeira, S. R. D. T. Siqueira, and G. M. Almeida, "Percutaneous radiofrequency rhizotomy and neurovascular 
decompression of the trigeminal nerve for the treatment of facial pain," Arquivos de Neuro-Psiquiatria, vol. 64, no. 4, pp. 983-989, 2006.

[18] M. Bozkurt, E. S. M. Al-Beyati, M. Ozdemir et al., "Management of bilateral trigeminal neuralgia with trigeminal radiofrequency rhizotomy: a treatment strategy for the lifelong disease," Acta Neurochirurgica, vol. 154, no. 5, pp. 785-792, 2012.

[19] B. Huang, M. Yao, Z. Feng et al., "CT-guided percutaneous infrazygomatic radiofrequency neurolysis through foramen rotundum to treat V2 trigeminal neuralgia," Pain Medicine, vol. 15, no. 8, pp. 1418-1428, 2014.

[20] X. Li, J. Ni, L. Yang et al., "A prospective study of Gasserian ganglion pulsed radiofrequency combined with continuous radiofrequency for the treatment of trigeminal neuralgia," Journal of Clinical Neuroscience, vol. 19, no. 6, pp. 824-828, 2012.

[21] Y. Kanpolat, A. Savas, A. Bekar, and C. Berk, "Percutaneous controlled radiofrequency trigeminal rhizotomy for the treatment of idiopathic trigeminal neuralgia: 25-year experience with 1600 patients," Neurosurgery, vol. 48, no. 3, pp. 524-534, 2001.

[22] J. M. Taha, J. M. Tew, and C. R. Buncher, "A prospective 15year follow up of 154 consecutive patients with trigeminal neuralgia treated by percutaneous stereotactic radiofrequency thermal rhizotomy," Journal of Neurosurgery, vol. 83, no. 6, pp. 989-993, 1995.

[23] G.-H. Lai, Y.-Z. Tang, X.-P. Wang, H.-J. Qin, and J.-X. Ni, "CT-guided percutaneous radiofrequency thermocoagulation for recurrent trigeminal neuralgia after microvascular decompression," Medicine, vol. 94, no. 32, p. e1176, 2015.

[24] F. Nie, D. Su, Y. Shi et al., "A prospective study of X-ray imaging combined with skin stimulation potential-guided percutaneous radiofrequency thermocoagulation of the Gasserian ganglion for treatment of trigeminal neuralgia," Pain Medicine, vol. 15, no. 9, pp. 1464-1469, 2014.

[25] W. Fouad, "Management of trigeminal neuralgia by radiofrequency thermocoagulation," Alexandria Journal of Medicine, vol. 47, no. 1, pp. 79-86, 2011.

[26] T. Inoue, H. Hirai, A. Shima, F. Suzuki, T. Fukushima, and M. Matsuda, "Diagnosis and management for trigeminal neuralgia caused solely by venous compression," Acta Neurochirurgica, vol. 159, no. 4, pp. 681-688, 2017.

[27] A. A. Kemeny, "Long-term outcomes of microvascular decompression and Gamma Knife surgery for trigeminal neuralgia: a retrospective comparison study," Acta Neurochirurgica, vol. 159, no. 11, p. 2137, 2017.

[28] Q. Wan, D. Zhang, X. Cao, Y. Zhang, M. Zhu, and W. Zuo, "CT-guided selective percutaneous radiofrequency thermocoagulation via the foramen rotundum for isolated maxillary nerve idiopathic trigeminal neuralgia," Journal of Neurosurgery, vol. 128, no. 1, pp. 211-214, 2018.

[29] Y. Li, L. Yang, J. Ni, and Z. Dou, "Microvascular decompression and radiofrequency for the treatment of trigeminal neuralgia: a meta-analysis," Journal of Pain Research, vol. 12, pp. 1937-1945, 2019.

[30] S. Kosugi, M. Shiotani, Y. Otsuka et al., "Long-term outcomes of percutaneous radiofrequency thermocoagulation of gasserian ganglion for 2nd- and multiple-division trigeminal neuralgia," Pain Practice, vol. 15, no. 3, pp. 223-228, 2015.

[31] H. P. Smith, J. M. McWhorter, and V. R. Challa, "Radiofrequency neurolysis in a clinical model. Neuropathological correlation," Journal of Neurosurgery, vol. 55, no. 2, pp. 246-253, 1981.
[32] W.-X. Zhao, Q. Wang, M.-W. He, L.-Q. Yang, B.-S. Wu, and J.-X. Ni, "Radiofrequency thermocoagulation combined with pulsed radiofrequency helps relieve postoperative complications of trigeminal neuralgia," Genetics and Molecular Research, vol. 14, no. 3, pp. 7616-7623, 2015.

[33] B. C. Son, H. S. Kim, I.-S. Kim et al., "Percutaneous radiofrequency thermocoagulation under fluoroscopic imageguidance for idiopathic trigeminal neuralgia," Journal of Korean Neurosurgical Society, vol. 50, no. 5, pp. 446-452, 2011.

[34] P. Yao, Y.-y. Deng, T. Hong et al., "Radiofrequency thermocoagulation for V2/V3 idiopathic trigeminal neuralgia," Medicine, vol. 95, no. 26, p. e4019, 2016.

[35] J. T. Yang, M. Lin, M. H. Lee et al., "Percutaneous trigeminal nerve radiofrequency rhizotomy guided by computerized tomography with three-dimensional image reconstruction," Chang Gung Medical Journal, vol. 33, no. 6, pp. 679-683, 2010.

[36] P. Yao, T. Hong, Y.-q. Zhu et al., "Efficacy and safety of continuous radiofrequency thermocoagulation plus pulsed radiofrequency for treatment of V1 trigeminal neuralgia," Medicine, vol. 95, no. 44, p. e5247, 2016.

[37] M. V. Koning, N. J. Koning, H. M. Koning, and M. van Kleef, "Relationship between sensory stimulation and side effects in percutaneous radiofrequency treatment of the trigeminal ganglion," Pain Practice, vol. 14, no. 7, pp. 581-587, 2014.

[38] Q. D. Huang, X. M. Liu, J. S. Chen et al., "The effectiveness and safety of thermocoagulation radiofrequency treatment of the ophthalmic division (V1) and/or maxillary (V2) and mandibular (V3) division in idiopathic trigeminal neuralgia: an observational study," Pain Physician, vol. 19, no. 7, pp. E1041-E1047, 2016.

[39] A. Elawamy, E. E. M. Abdalla, and G. A. Shehata, "Effects of pulsed versus conventional versus combined radiofrequency for the treatment of trigeminal neuralgia: a prospective study," Pain Physician, vol. 20, no. 6, pp. E873-E881, 2017.

[40] S. Erdine, N. S. Ozyalcin, A. Cimen, M. Celik, G. K. Talu, and R. Disci, "Comparison of pulsed radiofrequency with conventional radiofrequency in the treatment of idiopathic trigeminal neuralgia," European Journal of Pain, vol. 11, no. 3, pp. 309-313, 2007.

[41] S. Zheng, B. Wu, Y. Zhao et al., "Masticatory muscles dysfunction after CT-guided percutaneous trigeminal radiofrequency thermocoagulation for trigeminal neuralgia: a detailed analysis," Pain Practice, vol. 15, no. 8, pp. 712-719, 2015.

[42] P. Liu, W. Zhong, C. Liao, M. Yang, and W. Zhang, "The role of percutaneous radiofrequency thermocoagulation for persistent or recurrent trigeminal neuralgia after surgery," Journal of Craniofacial Surgery, vol. 27, no. 8, pp. e752-e755, 2016.

[43] F. C. Vinas, L. Zamorano, M. Dujovny et al., "In vivo and in vitro study of the lesions produced with a computerized radiofrequency system," Stereotactic and Functional Neurosurgery, vol. 58, no. 1-4, pp. 121-133, 1992.

[44] H. V. I. Easwer, N. Chatterjee, A. Thomas, K. Santhosh, K. T. Raman, and R. Sridhar, "Usefulness of flat detector CT (FD-CT) with biplane fluoroscopy for complication avoidance during radiofrequency thermal rhizotomy for trigeminal neuralgia," Journal of NeuroInterventional Surgery, vol. 8, no. 8 , pp. $830-833,2016$

[45] M. E. Sluijter, A. Teixeira, V. Serra, S. Balogh, and P. Schianchi, "Intra-articular application of pulsed radiofrequency for arthrogenic pain-report of six cases," Pain Practice, vol. 8, no. 1, pp. 57-61, 2008. 
[46] J. V. Zundert, S. Brabant, E. V. de Kelft, A. Vercruyssen, and J.-P. V. Buyten, "Pulsed radiofrequency treatment of the gasserian ganglion in patients with idiopathic trigeminal neuralgia," Pain, vol. 104, no. 3, pp. 449-452, 2003.

[47] J. H. Kim, H. Y. Yu, S. Y. Park, S. C. Lee, and Y. C. Kim, "Pulsed and conventional radiofrequency treatment: which is effective for dental procedure-related symptomatic trigeminal neuralgia?" Pain Medicine, vol. 14, no. 3, pp. 430-435, 2013.

[48] F. Luo, Y. Shen, T. Wang et al., "3D CT guided pulsed radiofrequency treatment for trigeminal neuralgia," Pain Practice, vol. 14, no. 1, pp. 16-21, 2014.

[49] T. Arıcı, M. Kurcaloğlu, E. Kılıç, and E. Erhan, "Radiofrequency thermocoagulation combined with pulsed radiofrequency for gasserian ganglion blockage," Agri, vol. 30, no. 4, pp. 179-182, 2018.

[50] F. Luo, L. Meng, T. Wang, X. Yu, Y. Shen, and N. Ji, "Pulsed radiofrequency treatment for idiopathic trigeminal neuralgia: a retrospective analysis of the causes for ineffective pain relief," European Journal of Pain, vol. 17, no. 8, pp. 1189-1192, 2013.

[51] N. H. L. Chua, W. Halim, T. Beems, and K. C. Vissers, "Pulsed radiofrequency treatment for trigeminal neuralgia," Anesthesiology and Pain Medicine, vol. 1, no. 4, pp. 257-261, 2012.

[52] S.-j. Xu, W.-h. Zhang, T. Chen, C.-y. Wu, and M.-d. Zhou, "Neuronavigator-guided percutaneous radiofrequency thermocoagulation in the treatment of intractable trigeminal neuralgia," Chinese Medical Journal, vol. 119, no. 18, pp. 1528-1535, 2006.

[53] N. Wang and Y. S. Hu, "Clinical efficacy of the combination of neuronavigation and electrophysyological monitoring techniques percutaneous radiofrequency thermocoagulation therapy for the treatment of trigeminal neuralgia," Chinese Journal of Pain Medicine, vol. 22, no. 11, pp. 823-827, 2016. 